\title{
Effect of Various PCBM Doping on the Interfacial Layer of Al/PCBM:ZnO/p-Si Photodiodes
}

Teoman Öztürk ( $\nabla$ teozturk@gmail.com )

Selcuk Universitesi Fen Fakultesi https://orcid.org/0000-0002-5002-5412

\section{Research Article}

Keywords: Photodiode, photodetector, electrical characterization, Al/PCBM, ZnO/p-Si device

Posted Date: February 26th, 2021

DOI: https://doi.org/10.21203/rs.3.rs-247649/v1

License: (c) (i) This work is licensed under a Creative Commons Attribution 4.0 International License. Read Full License

Version of Record: A version of this preprint was published at Journal of Materials Science: Materials in Electronics on March 18th, 2021. See the published version at https://doi.org/10.1007/s10854-02105674-3. 


\title{
Effect of various PCBM doping on the interfacial layer of Al/PCBM:ZnO/p-Si photodiodes
}

\author{
Teoman Öztürk \\ Selcuk University, Faculty of Science, Department of Physics, 42130 Konya, Turkey
}

E-mail: teozturk@gmail.com

\begin{abstract}
The light can be detected by various devices such as photoconductors, photodetectors, phototransistors, solar cells and photodiodes, and the light can be employed energy harvesting as well as sensing applications. Various materials can be utilized to raising of the efficiency of light-based devices. In present study, metalsemiconductor (MS) devices with various [6,6]-Phenyl C61-butyric acid methyl ester (PCBM) doped zinc oxide $(\mathrm{ZnO})$ interfacial layer were fabricated for photodiode applications. Commercially purchased PCBM and $\mathrm{ZnO}$ were mixed in order to obtain undoped, 3\%, 5\%, and 10\% PCBM doped $\mathrm{ZnO}$ interfacial layer for Al/PCBM:ZnO/p-Si devices. The obtained solutions were layered on the p-type silicon ( $p$-Si) substrades by spin coating method. The thermal evaporation technique was utilized to deposit Al metal electrodes both back and front sides. The morphological properties of the fabricated devices were characterized by AFM. The morphological images of the AFM revealed that PCBM doping affected the surface morphology as well as surface roughness of the $\mathrm{ZnO}$ layers. $I-V$ measurements were carried out in the dark and under varying illumination conditions for electrical properties. The devices exhibited good rectifying properties at around $10^{3}$ rates, both dark and various illumination conditions, according to $I-V$ graphs. The junction parameters of the produced devices were determined by using thermionic emission, Norde, and Cheung models from the $I-V$ characteristics of the devices. The devices have high ideality factors and these values generally fluctuate with varying PCBM doping amounts. The current transient measurements show that PCBM doping provide increasing in the light response capacity. According to the results, the devices can be employed as photodiode and photodetector applications for the further works in the industry.
\end{abstract}

Keywords: Photodiode; photodetector; electrical characterization; Al/PCBM:ZnO/p-Si device.

\section{Introduction}

Metal and semiconductor (MS) junctions are employed in the diode, transistor, and capacitors for many years because of their essential junction properties [1-4]. The MS junctions are crucial in optoelectronic devices particularly in photovoltaic cells, photodetectors and photodiodes [5-7]. The photodiodes work at reverse biases and provide detection of the light in a good sensitivity and use in a smoke detector, compact disk players, and 
switching like applications [8-12]. Many materials for photodiode applications of the MS devices were studied by the researchers [13-15]. Generally, a metal oxide or polymer layers are inserted in the interface of the MS junction to control electrical properties and to improve the detection amount of the light because of fabricating more powerful photodiode devices [16,17]. Metal oxide semiconductors have been tremendously studied due to their good optical, chemical and electrical properties. Zinc oxide $(\mathrm{ZnO})$ is a kind of popular metal oxide semiconductor and have found wide employments in optoelectronic devices because of its distinctive optical, gas sensing, structural and electrical properties. $\mathrm{ZnO}$ has some main advantages such as wide and direct band gap (3.37 eV), high exciton binding energy $(60 \mathrm{meV})$, low-cost, transparent conductivity and non-toxicity and also exhibits dual semiconducting and piezoelectric properties [18-21]. With these excellent properties, $\mathrm{ZnO}$ have found wide application in various devices such as phototransistors [22], nanometer gas sensors [23], dyesensitized solar cells [24], photodetectors [25] and photodiodes [26]. Many methods such as chemical spray pyrolysis [27], SILAR [28], spin coating [29], hydrothermal [30], atomic layer deposition [31], thermal evaporation [32] and RF magnetron sputtering [33] etc. are utilized to fabricate the $\mathrm{ZnO}$ thin film layer. Among these methods, spin coating is an inexpensive and easy method to acquire good uniform film behaviors [34,35].

In order to improve electro-optic properties of $\mathrm{ZnO}$ containing devices, it can be doped or composed easily with other transition metals or organic materials [36-41]. Organic materials have attracted much interest for optoelectronic applications due to low cost, flexibility, and wearability of organic materials [42-45]. Among the organics, carbonaceous materials (amorphous carbon, carbon nanotube, diamond, graphene, fullerene, etc.) draw great attention and are extensively used in optoelectronic device applications because of their unique structural and electronic properties. Nie et al. [46] fabricated a graphene- $\mathrm{ZnO}$ photodetector by coating $\mathrm{ZnO}$ nanorod arrays with a monolayer graphene layer. Cheng et al. [47] investigated a photodetector based on graphene/ZnO/Si triple junctions. Shao et al. [48] produced a $\mathrm{ZnO}$ nanowires/p-Si heterojunction photodiode using a multiwalled carbon nanotubes. Bazargan et al. [49] employed a photodetector based on reduced graphene oxide (rGO) and $\mathrm{ZnO}$ thin film. Koç et al. [50] fabricated and investigated current-voltage characteristics of $\mathrm{ZnO}$-amorphous carbon photodiodes.

Among the carbonaceous materials, PCBM, which is a fullerene derivative, is one the most studied materials in organic photovoltaic cells for the bulk-heterojunction structure [51]. PCBM has $n$-type semiconducting property and is mainly used as electron acceptor for solar cells due to its high electron mobility [52-55]. Furthermore, PCBM can be used for dispersing of other material efficiently via blending and remain stable [56]. This behavior of PCBM provides the opportunity to use it with other organic and inorganic materials [57,58]. In the literature, PCBM was studied in p-Si/PCBM hybrid organic/inorganic semiconductor photodiodes by Yakuphanoglu [59]. PCBM:ZnO interlayer was used in a Al/PCBM:ZnO/p-Si heterojunction for photodiode applications by Gullu et al [60].

This study focuses on the effect of various amounts of PCBM on Al/PCBM:ZnO/p-Si photodiodes. With the intention to realize the effect of the various amounts of PCBM on the electrical properties of the $\mathrm{Al} / p$-Si devices, undoped and various PCBM amounts doped $\mathrm{ZnO}$ thin film layers for interfacial materials in the $\mathrm{Al} / p$-Si were manufactured by spin coating method. The surface morphology of the PCBM doped ZnO interfacial layers were investigated by AFM. Moreover, photodetection behaviors of the obtained various PCBM doped $\mathrm{ZnO}$ Al/PCBM:ZnO/p-Si devices were investigated by employing $I-V$ measurements. 


\section{Experimental details}

PCBM was purchased from Sigma-Aldrich and used as received without further purification. First, PCBM was dissolved in 1-2 dichlorobenzene ( $25 \mathrm{~g} / \mathrm{L}$ concentration) and stirred for $3 \mathrm{~h}$ at $60^{\circ} \mathrm{C}$ in a dried nitrogen atmosphere to obtain the PCBM solution. Secondly, the PCBM:ZnO organic blend was prepared using zinc acetate dehydrate $\left(\mathrm{Zn}\left(\mathrm{C}_{2} \mathrm{H}_{3} \mathrm{O}_{2}\right) 2 \cdot 2 \mathrm{H}_{2} \mathrm{O}\right)$ as a precursor material. For this blend, the $\mathrm{Zn}\left(\mathrm{C}_{2} \mathrm{H}_{3} \mathrm{O}_{2}\right) 2 \cdot 2 \mathrm{H}_{2} \mathrm{O}$ was dissolved in methanol as $0.2 \mathrm{M}$ and mixed with PCBM to achieve undoped, 3\%, 5\%, and 10\% molar ratio in different vessels, and then the mixtures were stirred for one night. Thirdly, a $p$-type silicon substrate, which has $600 \mu \mathrm{m}$ thickness, 5-10 $\Omega . \mathrm{cm}$ resistivity, and (111) orientation, was sliced into pieces with an area of $2 \mathrm{~cm}^{2}$ and, then the parts were cleaned in acetone and propanol by an ultrasonic cleaner. Fourthly, impurities, and native oxide layer from the surface of the wafer pieces were removed with dumping into $\mathrm{HF}: \mathrm{H}_{2} \mathrm{O}(1: 1)$ solution for 30 seconds. Fifthly, in order to place ohmic contact on the back surface of the wafer pieces, a $100 \mathrm{~nm}$ aluminum layer was deposited by thermal evaporation. Then the pieces were annealed in $\mathrm{N}_{2}$ medium for 5 minutes at $570 \square \mathrm{C}$. Sixthly, prepared PCBM:ZnO blend solutions were coated on $p$-Si substrates by Fytronix SC500 spin coater at 1500 rpm spinning rate for $30 \mathrm{~s}$. Subsequently, to evaporate the solvents of the samples, they were thermally heated on a hot plate at $150{ }^{\circ} \mathrm{C}$ for 15 minutes. Lastly, for achieving rectifying contact on the various PCBM doped ZnO layers, $150 \mathrm{~nm}$ thicknesses Al layer was vaporized by thermal evaporator via a hole array mask for $3.14 \times 10^{-2} \mathrm{~cm}^{2}$ contact area. The schematic drawing of the fabricated device as well as band diagram has been shown in Fig. 1. Here, the $p$-Si behaves substrate as well as semiconductor layer to collect carriers from metal to semiconductor. Thus, the rectifying behavior occurs due to their work function differences.

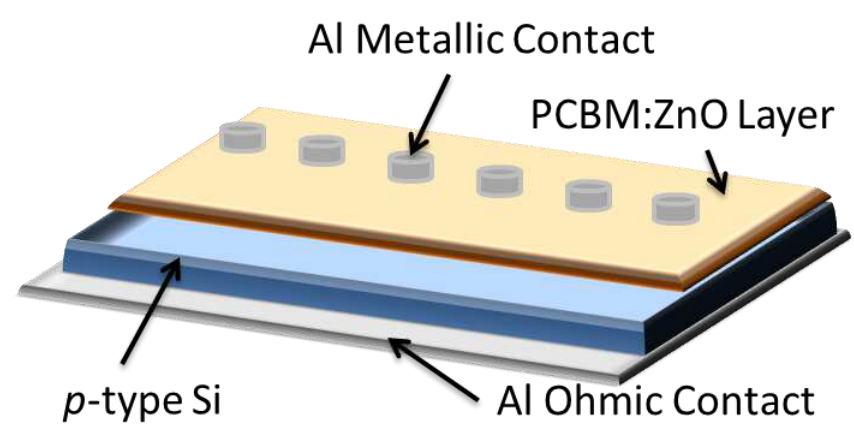

Figure 1. The schematic drawing and band diagrams of the fabricated Al/PCBM:ZnO/p-Si devices

The surface morphologies of the obtained devices were taken by the PARK system XE 100E model AFM. I$V$ characteristics were measured by Fytronix FY-7000 photovoltaic characterization system in the dark and under varying illumination conditions in the range of $-5 \mathrm{~V}$ and $+5 \mathrm{~V}$ voltage range. The wavelength of the used light source was in between 400-1100 nm.

\section{Results and discussion}


The surface morphologies of the undoped and various PCBM doped Al/PCBM:ZnO/p-Si devices were studied by AFM measurements. Fig. 2 indicates the 2D and 3D AFM morphology pictures of the undoped and various PCBM doped $\mathrm{ZnO}$ interfacial layers of the Al/PCBM:ZnO/p-Si devices. Roughness average values of the surfaces are $1.85119 \mathrm{~nm}, 1.78219 \mathrm{~nm}, 1.60102 \mathrm{~nm}$ and $2.57157 \mathrm{~nm}$ for undoped, 3\%, 5\% and 10\% PCBM doped devices, respectively. On the other hand, root mean square values of surface roughness of the devices are 2.31406 $\mathrm{nm}, 2.25092 \mathrm{~nm}, 2.1219 \mathrm{~nm}$ and $3.49079 \mathrm{~nm}$ for undoped, 3\%, 5\% and 10\% PCBM doped devices, respectively.
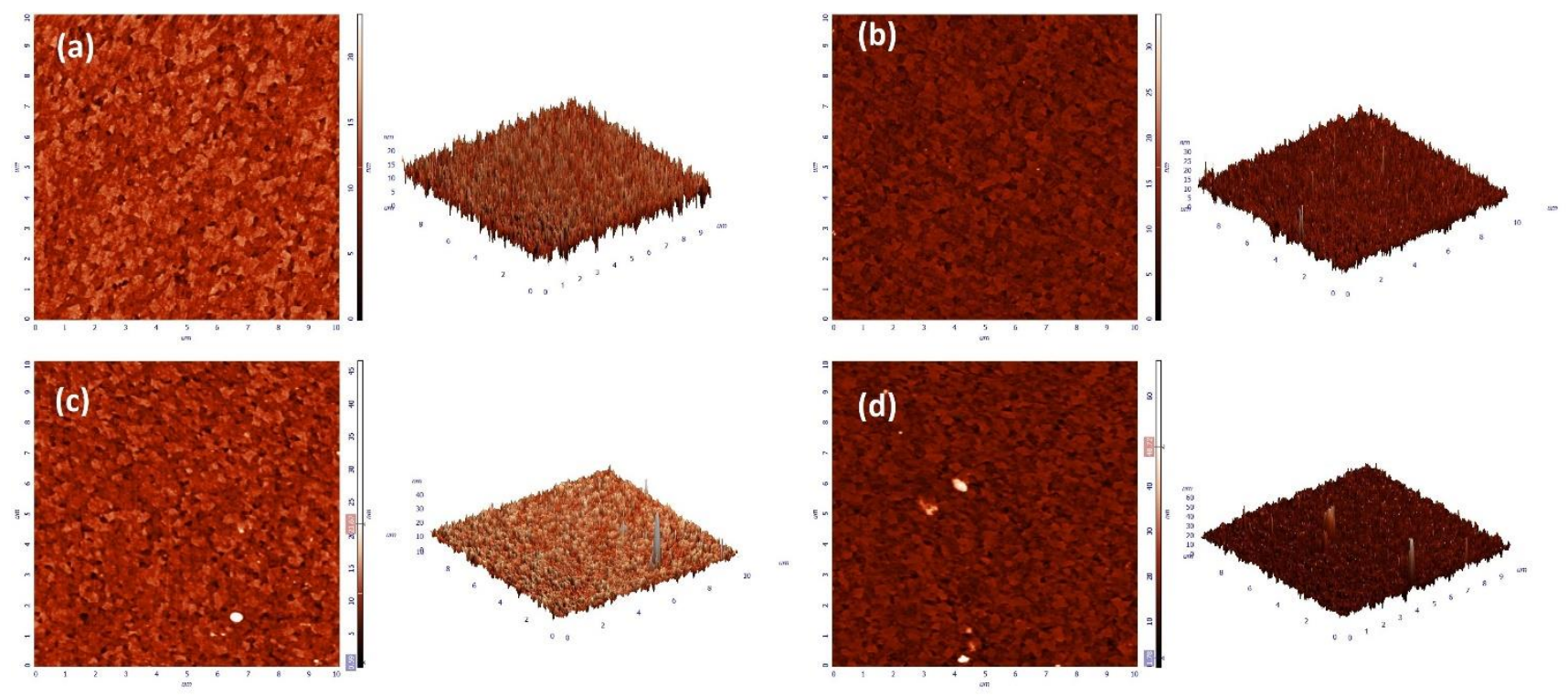

Figure 2. The AFM morphology pictures of a) undoped b) $3 \%$, c) $5 \%$ and d) $10 \%$ PCBM doped Al/PCBM:ZnO/p-Si devices

The $I-V$ characteristics of the undoped and 3\%, 5\%, and 10\% PCBM doped Al/PCBM:ZnO/p-Si devices have been exhibited in Fig. 3. The performed devices showed good rectifying property and their rectifying ratio $(R R)$ values have been given in Table 1. The 3\% PCBM doped device has the highest $R R$ value of $2.54 \square 10^{4}$ among the devices due to suitable amount of the PCBM in PCBM-ZnO layer. Thus, the PCBM doped ZnO layer has more carriers and causes to higher current in forward biases. Furthermore, PCBM doping caused to decrease the leakage current at high voltages, especially 5\% and 10\% PCBM doping after 3\% PCBM doping level. The doping of the PCBM to the $\mathrm{ZnO}$ did not change the leakage current so much because the PCBM may serve only to increase the number of carriers in the interface of the device. Usually, low leakage current requires high barrier height, but there is deviation here due to having PCBM in the interface. The PCBM may cause to ease carrier transition in the interface and give low barrier height. The devices have displayed rectifying property even if they are under illumination conditions. This result can be assigned to the dielectric properties of the $\mathrm{ZnO}$ interfacial layer [61]. The reverse current of the devices did not increase with increasing light illumination like $\mathrm{Al} / \mathrm{ZnO} / p$-Si device (displayed in Fig. 3a) because PCBM layers may behave electron acceptor layer in the interface of the devices. Thus, photocurrent of the devices did not increase with increasing light illumination at reverse biases. However, obtained all devices have a various response to the light illumination at reverse biases. This behavior highlighted that Al/PCBM:ZnO/p-Si devices could be employed as photodiodes and photodetector applications [60]. 
Moreover, the increasing current with increasing light intensity as well as shifting of minimum current to positive side highlights that the fabricated devices can be viewed as photovoltaic devices, but their efficiencies usually low $[1,62,63]$
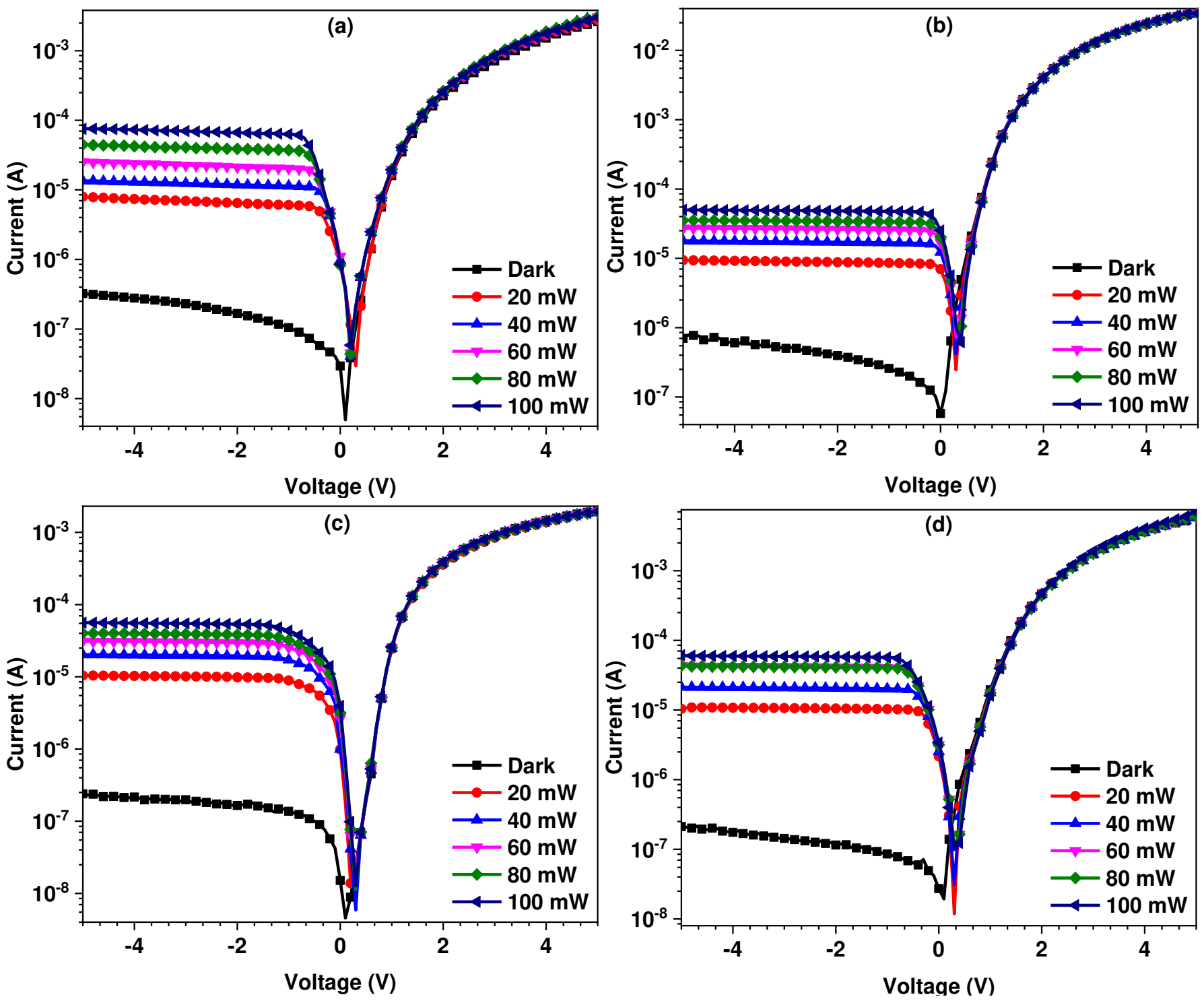

Figure 3. $I-V$ plots of a) undoped b) 3\%, c) 5\% and d) 10\% PCBM doped Al/PCBM:ZnO/p-Si devices

The $I$ - $V$ characteristics of the undoped and various PCBM doped Al/PCBM:ZnO/p-Si devices were compared for dark and $100 \mathrm{~mW}$ light power intensity in Fig 4. The leakage currents increased with 3\% PCBM doping, then slightly decreased with increasing PCBM doping in the dark. However, the leakage currents were almost stayed constant under $100 \mathrm{~mW}$ light power intensity condition for various PCBM doping levels. The forward bias currents increased with increasing PCBM doping, but maximum values were obtained for 3\% PCBM doped device both in the dark and under $100 \mathrm{~mW}$ light illumination. The slope of the second region in forward bias is highest for 5\% PCBM doping, and smallest ideality factor was obtained for 5\% PCBM doping. However, the $I$ $V$ characteristics of the 5\% PCBM doped device immediately bent at around $1.5 \mathrm{~V}$ forward bias and it has highest 
series resistance. Both 3\% and \%10 PCBM doped devices bent at around $2 \mathrm{~V}$ forward bias and had lower series resistance. This fluctuation can be attributed to agglomerations of the organic PCBM [64].
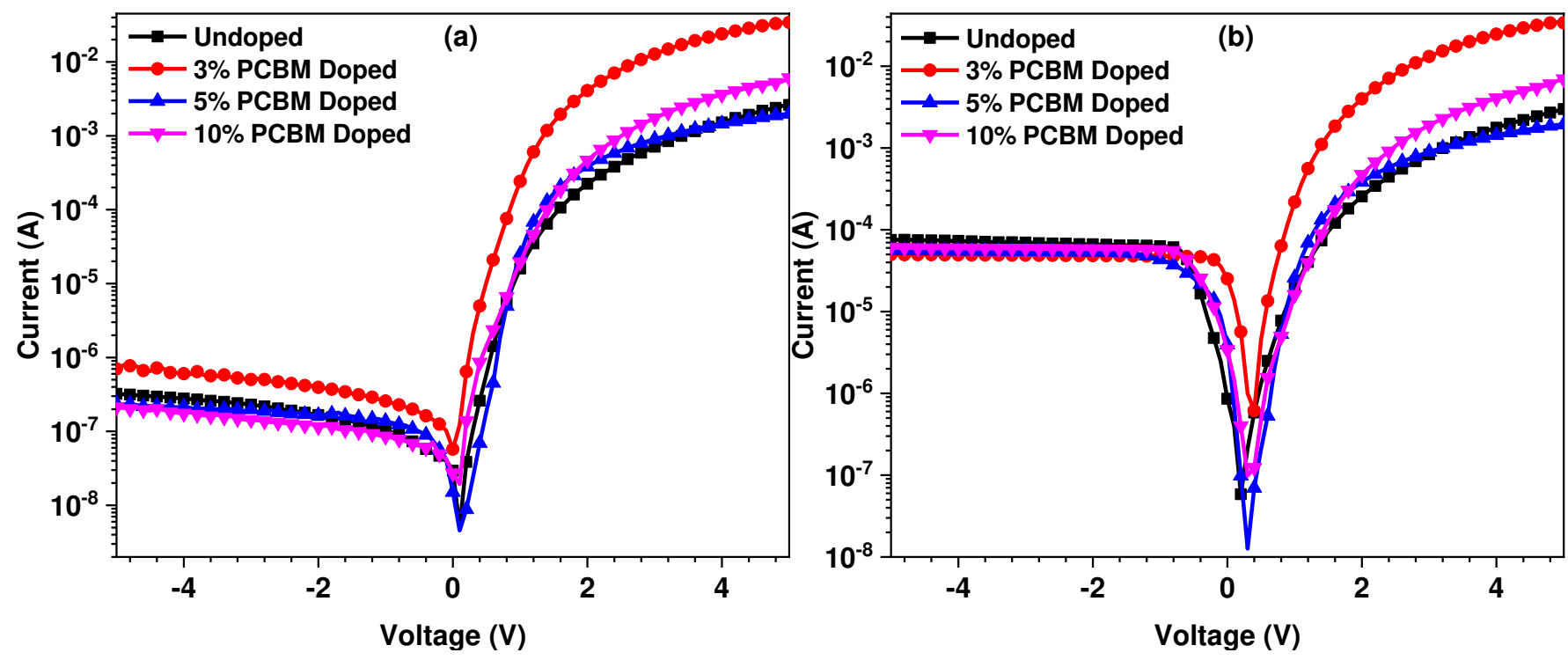

Figure 4. $I-V$ plots of the undoped and various PCBM amounts doped Al/PCBM:ZnO/p-Si devices a) in the dark and b) under $100 \mathrm{~mW}$ light intensity for comparison

The obtained devices were characterized by $I-V$ measurements for determining of the diode parameters such as ideality factor $(n)$, barrier height $\left(\Phi_{b}\right)$ and series resistance $\left(R_{s}\right)$ by various methods. According to the results, the $I-V$ measurements show a non-linear attitude and this kind of characteristics is interpreted via thermionic emission (TE) model [65]. $n$ and $\Phi_{b}$ can be acquired from $I-V$ characteristics using TE model where the current $(I)$ is given as the following equation [66]:

$$
I=I_{0} \exp \left(\frac{q V}{n \mathrm{k} T}\right)\left[1-\exp \left(-\frac{q V}{n \mathrm{k} T}\right)\right]
$$

where $I_{0}$ is the saturation current and expressed as [67]:

$$
I_{0}=A A^{*} T^{2} \exp \left(-\frac{q \Phi_{b}}{\mathrm{k} T}\right)
$$

where $A$ is the contact area $\left(A=3.14 \times 10^{-2} \mathrm{~cm}^{2}\right), A^{*}$ is Richardson constant, $T$ is temperature, $\mathrm{k}$ is Boltzmann constant, $q$ is the electronic charge and $V$ is the applied bias voltage. The $n$ and $\Phi_{b}$ are obtained by following relations when the $V \geq 3 \mathrm{kT} / q[68,69]$.

$$
n=\frac{q}{\mathrm{k} T}\left(\frac{d V}{d \ln I}\right)
$$

and 


$$
\Phi_{b}=\frac{\mathrm{k} T}{q} \ln \left(\frac{A^{*} A T^{2}}{I_{0}}\right)
$$

The calculated $n$ and $\Phi_{b}$ values as well as saturation currents have been indicated in Table 1 for undoped and various PCBM doped Al/PCBM:ZnO/p-Si devices. While the value of $n$ increases from 4.47 to 5.47 with increasing PCBM doping level from 0 to $3 \%$, $\Phi_{b}$ decreases from $0.74 \mathrm{eV}$ to $0.69 \mathrm{eV}$. The value of $n$ decreases to 3.89 , but $\Phi_{b}$ increases to $0.79 \mathrm{eV}$ for a 5\% PCBM doping level. In the case of $10 \%$ PCBM doping, $n$ increases up to 7.45 , and $\Phi_{b}$ decreases to $0.68 \mathrm{eV}$. Generally, $n$ values are expected close to unity however the obtained ideality factor values here are higher than unity due to barrier inhomogeneity and interface states as well as interfacial PCBM doped $\mathrm{ZnO}$ layer [70,71]. When the saturation current value of the PCBM undoped device is $9.40 \square 10^{-9} \mathrm{~A}$, it increased up to $5.47 \square 10^{-7} \mathrm{~A}$ by $10 \%$ PCBM doping. However, the minimum value of the saturation current was obtained for a 5\% PCBM doping level.

Light generally causes increasing of carriers in the interface of the MS devices, and this induces an increase in the current at reverse biases [72,73]. Here, the increasing light illumination generated charge carriers in the interface of the various PCBM doped Al/PCBM:ZnO/p-Si devices, and current at reverse biases increased for all devices with increasing light illumination intensity. However, the devices still survived their rectifying behaviors, according to Fig. 4. These results revealed that fabricated various PCBM doped Al/PCBM:ZnO/p-Si devices can be used in optoelectronic devices such as photodiodes or photodetectors [74]. Furthermore, the increasing speed of the reverse current decreased with PCBM doping due to the electron acceptor behavior of the PCBM. Here PCBM may have captured the electrons of the $\mathrm{ZnO}$, which induced by illumination, and transferred them to the $\mathrm{Al}$ electrode. However, the defect levels or interface states prevented this transferring process. Moreover, the current value at $5 \mathrm{~V}$ biases increased with a 3\% PCBM doping level and then decreased the lowest value for 5\% PCBM doping. This kind of fluctuation can be found in the literature depending on the PCBM doping or mixing level amount due to the agglomeration effect of $\mathrm{ZnO}$ [75]. Furthermore, the responsivity values of the various PCBM doped Al/PCBM:ZnO/p-Si devices were calculated and listed in Table 1. Whilst the undoped device has minimum responsivity, 3\% PCBM doped device has highest responsivity value. The obtained result verifies that the PCBM doping an increase the responsivity value.

Table 1. The device parameters of the devices for various PCBM doping

\begin{tabular}{|c|c|c|c|c|c|c|c|c|c|c|c|}
\hline $\begin{array}{c}\text { Doping } \\
\text { Level }\end{array}$ & $\begin{array}{c}\text { Saturation } \\
\text { Current } \\
\left(I_{0}\right)\end{array}$ & $\begin{array}{c}n \\
(T E) \\
- \\
\end{array}$ & $\begin{array}{c}n \\
\text { Cheung } \\
- \\
\end{array}$ & $\begin{array}{c}\Phi_{\boldsymbol{b}} \\
(\boldsymbol{T E}) \\
(\mathrm{eV})\end{array}$ & $\begin{array}{c}\Phi_{b} \\
\text { Cheung } \\
(\mathrm{eV})\end{array}$ & $\begin{array}{c}\Phi_{\boldsymbol{b}} \\
\text { Norde } \\
(\mathrm{eV})\end{array}$ & $\begin{array}{c}\boldsymbol{R}_{s} \\
\text { Norde } \\
(\mathrm{k} \square)\end{array}$ & $\begin{array}{c}\boldsymbol{R}_{\boldsymbol{s}} \\
\text { Cheung } \\
(\mathrm{k} \square(d \ln (I))\end{array}$ & $\begin{array}{c}\boldsymbol{R}_{\boldsymbol{s}} \\
\text { Cheung } \\
(\mathrm{k} \square(H(I))\end{array}$ & $\begin{array}{c}\boldsymbol{R} \boldsymbol{R} \\
\text { (at 3V) }\end{array}$ & $\begin{array}{c}\text { Responsivity } \\
(\mathrm{A} / \mathrm{W})\end{array}$ \\
\hline $0 \%$ & $9.40 \square 10^{-9}$ & 4.47 & 4.74 & 0.74 & 0.74 & $\overline{0.82}$ & 9.63 & 4.63 & 4.72 & $2.08 \square 10^{3}$ & 0.11 \\
\hline $3 \%$ & $6.01 \square 10^{-8}$ & 5.46 & 5.47 & 0.69 & 0.65 & 0.72 & 0.35 & 0.16 & 0.27 & $2.54 \square 10^{4}$ & 3.20 \\
\hline $5 \%$ & $1.25 \square 10^{-9}$ & 3.89 & 3.60 & 0.79 & $\overline{0.81}$ & 0.93 & 2.28 & 1.94 & 1.84 & $4.55 \square 10^{3}$ & 0.50 \\
\hline $10 \%$ & $5.47 \square 10^{-7}$ & 7.45 & 7.72 & 0.68 & 0.67 & 0.75 & 1.18 & 0.81 & 0.79 & $1.21 \square 10^{4}$ & 0.43 \\
\hline
\end{tabular}

Cheung or Norde models can be used to obtain once more junction parameters such as ideality factor and barrier height as well as series resistance $[76,77]$. The current, according to Cheung model, is given as follows: 


$$
I=I_{0} \exp \left(-\frac{\mathrm{q}\left(V-I R_{s}\right)}{n \mathrm{k} T}\right)
$$

where $I R_{s}$ represents a voltage drop because of the series resistance in the junction. The Eq. (6) can be rearranged, and below equations are obtained:

$$
\begin{aligned}
& \frac{d V}{d(\ln I)}=I R_{s}+n \frac{\mathrm{k} T}{\mathrm{q}} \\
& H(I)=V-n\left(\frac{\mathrm{k} T}{\mathrm{q}}\right) \ln \left(\frac{I}{A A^{*} T^{2}}\right)
\end{aligned}
$$

here $H(I)$ can be reorganized as:

$$
H(I)=I R_{s}+n \Phi_{b}
$$

From these equations, it is obvious that $d V / d(\ln I)$ vs I and $H(I)$ vs $I$ graphs display straight-line profile. While $d V / d(\ln I)$ versus $I$ graph gives $n$ and $R_{s}$ values from the $y$-intercept and slope of the plot, the $H(I)$ versus $I$ graph provides to determine the $\Phi_{b}$ and one of another $R_{s}$ values [78,79]. Fig. 5a-d show both the $d V / d(\ln I)$ and $H(I)$ versus $I$ graphs of the undoped and various PCBM doped Al/PCBM:ZnO/p-Si devices. The obtained graphs exhibited good linearity properly to Cheung model. The determined diode parameters have been arranged in Table 1. The obtained $n$ and $\Phi_{b}$ values are compatible with the results of the TE. The obtained $R_{s}$ values both the $d V / d(\ln I)$ and $H(I)$ versus $I$ plots are in agreement and verify the consistency of the Cheung model [80]. Furthermore, the $R_{S}$ values are high for undoped $\mathrm{ZnO}$ interfacial layer as $4.63 \mathrm{k} \Omega$, but decreased to $0.16 \mathrm{k} \Omega$ for $3 \%$ PCBM doping and increased up to $1.94 \mathrm{k} \Omega$ for $5 \%$ and decreased $0.79 \mathrm{k} \Omega$ for $10 \%$ PCBM doping again. The PCBM doping can reduce the $R_{s}$ effect of the Al/PCBM:ZnO/p-Si devices [81]. 

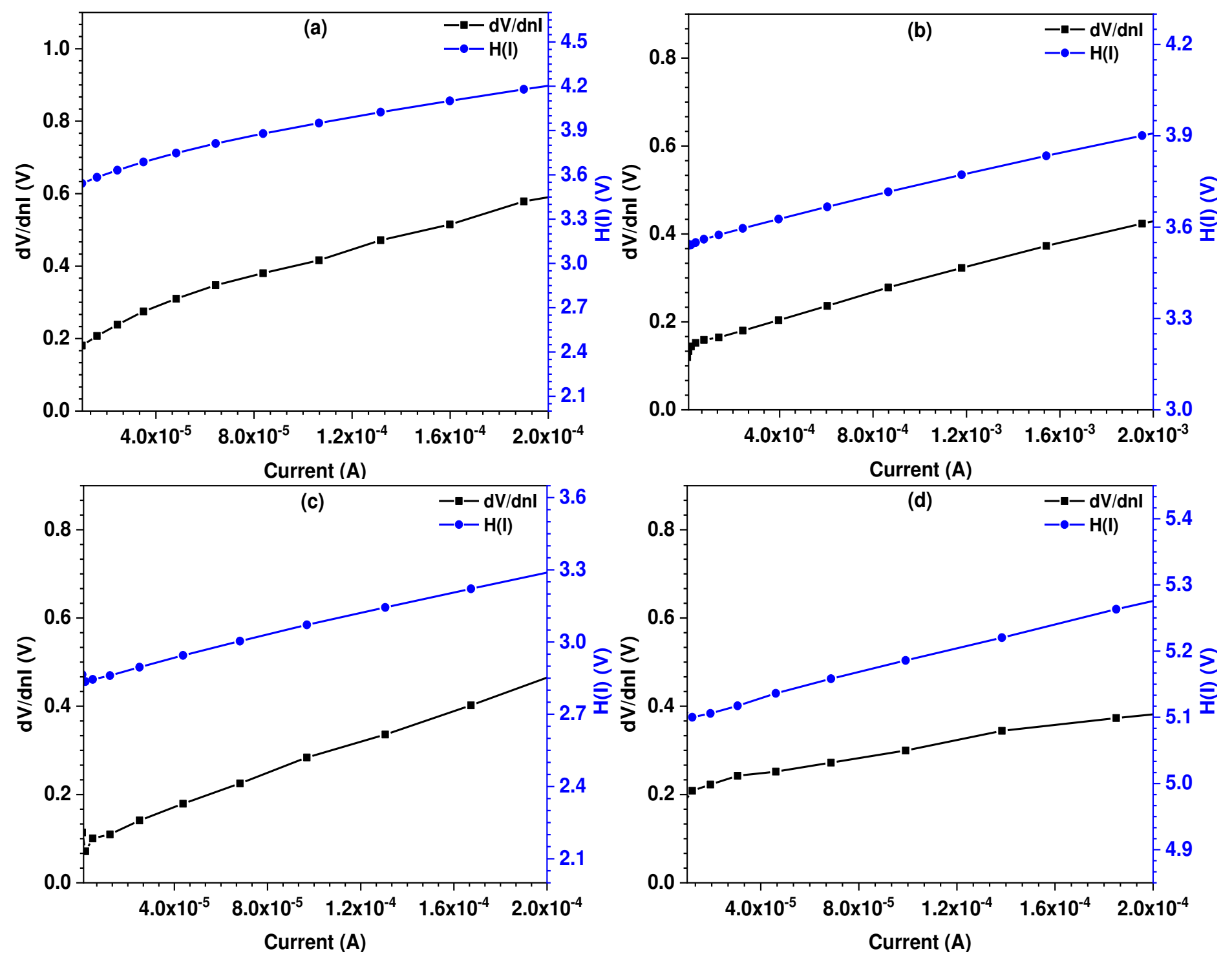

Figure 5. $d V / d(\ln I)-I$ and $H(I)-I$ plots of the Al/PCBM:ZnO/p-Si devices a) for undoped b) 3\%, c) $5 \%$ and d) $10 \%$ PCBM doped $\mathrm{ZnO}$ interlayer

Another way to determine the magnitudes of $\Phi_{b}$ and $R_{s}$ is the implementation of Norde model. Using this model, the Norde function is expressed as [82]:

$$
\begin{aligned}
& F(V) \\
& =\frac{V}{\gamma}-\frac{k T}{q} \ln \left(\frac{I(V)}{A A^{*} T^{2}}\right)
\end{aligned}
$$

In this equation, $\gamma$ is a dimensionless integer value greater than TE ideality factor and $I(V)$ is the current due to applied voltage experimentally. After the Norde function has been reorganized, the $\Phi_{b}$ and $R_{s}$ formulas are obtained as the following equations:

$$
\Phi_{b}=F\left(V_{0}\right)+\left[\frac{V_{0}}{\gamma}-\frac{k T}{q}\right]
$$




$$
R_{s}=\frac{\gamma-n}{I} \frac{k T}{q}
$$

where $V_{0}$ represents the minimum value of voltage related to the minimum value of the $F(V)$.

$F(V)-V$ plots of the undoped and different PCBM amount doped Al/PCBM:ZnO/p-Si devices have been depicted in Fig. 6a-d. The obtained plots are good agreement with the expected Norde plots. The values of $\Phi_{b}$ and $\mathrm{R}_{\mathrm{s}}$ for each device were determined from the Norde model and have been displayed in Table 1. The obtained $\Phi_{b}$ and $R_{s}$ values are higher than other values that obtained from the TE and Chung models due to approximation differences of the methods or non-ideal junction structure [83]. However, their variation with various PCBM doping amounts is the same as other models.
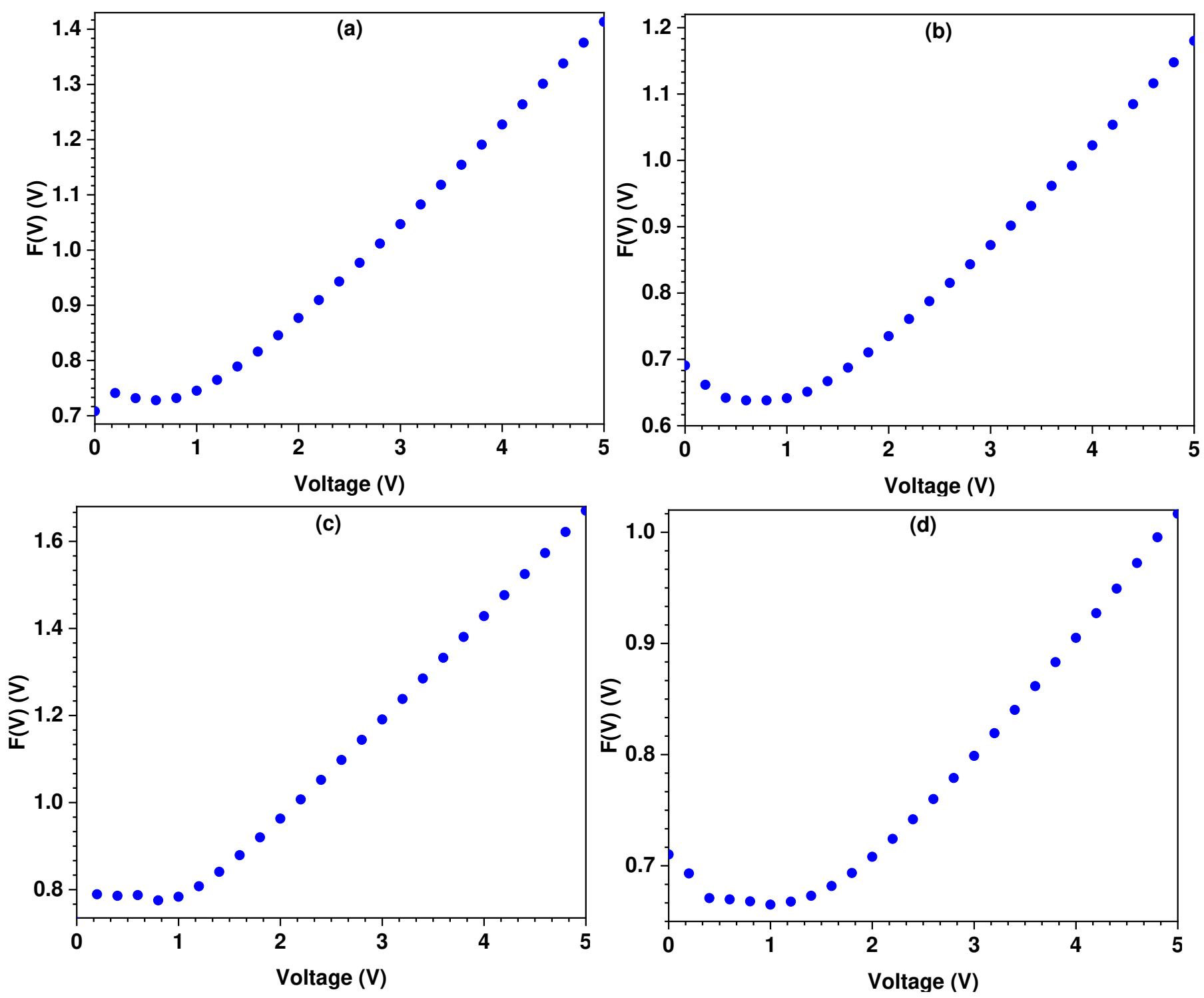

Figure 6. $F(V)-V$ graphs of the Al/PCBM:ZnO/p-Si devices a) for undoped b) $3 \%$, c) $5 \%$ and d) $10 \%$ PCBM doped $\mathrm{ZnO}$ interlayer 
The photoresponse properties of the devices can be studied by current transient measurements when the device both at on and off positions [6]. Fig. 7a-d indicate the current transient plots of the undoped and various PCBM doped Al/PCBM:ZnO/p-Si devices for 20, 40, 60, 80, and $100 \mathrm{~mW} / \mathrm{cm}^{2}$ light power intensities. All the devices have almost linearly increasing profile with growing light illumination intensity. The undoped, 3\% and 5\% PCBM doped devices have small increase with increasing light intensity at low illumination power and a significant increase at $100 \mathrm{~mW}$ illumination, but 10\% PCBM doped device usually has linear increase all illumination power range. When the devices are compared according to light response performances, the 10\% PCBM doped device has the highest performance due to having high photocurrent in a transient period. This result highlights that the PCBM can be used in the photodiode with correct doping amount to increase the detection control [84].
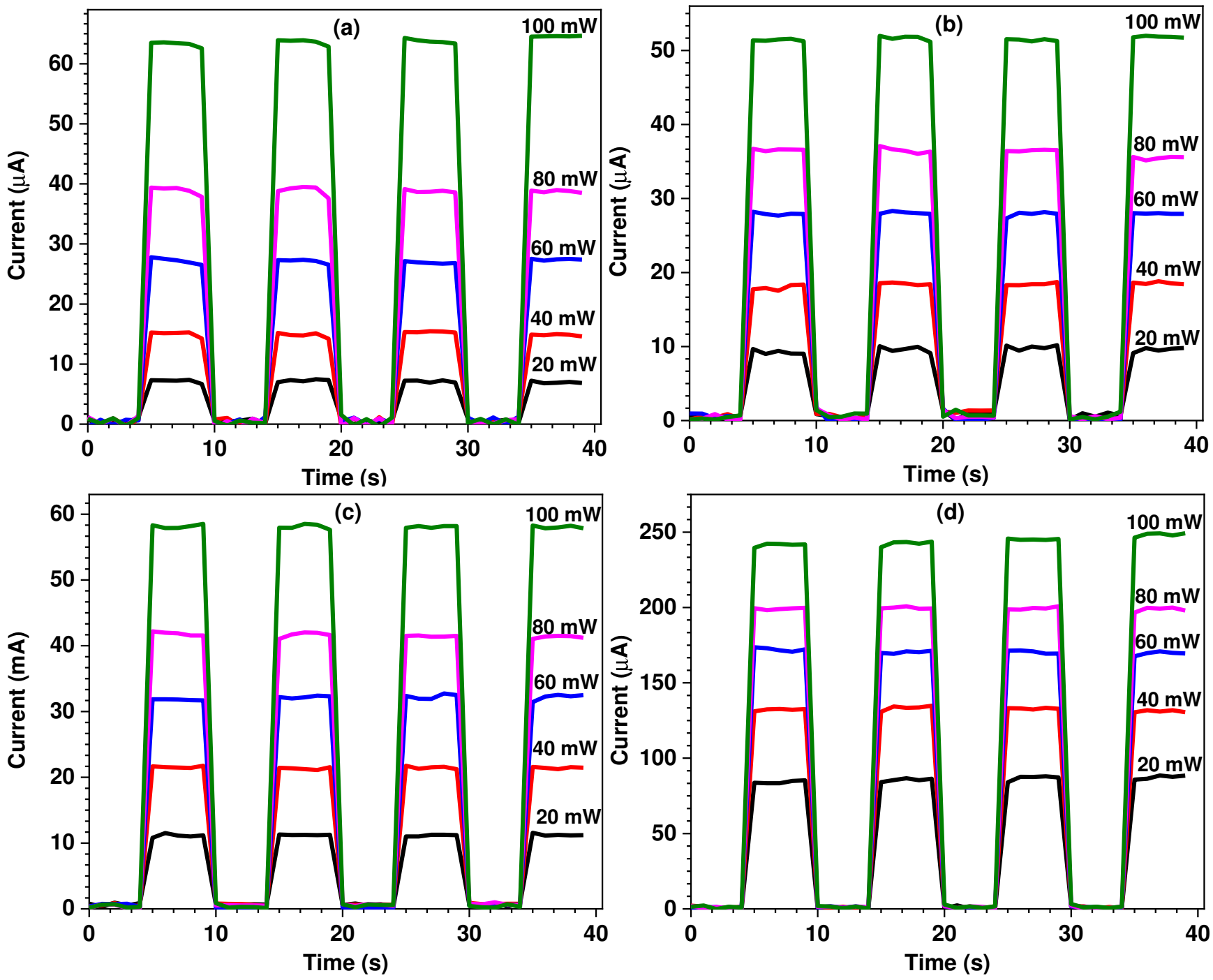

Figure 7. The current transient measurements of the various PCBM doped Al/PCBM:ZnO/p-Si devices a) for undoped b) $3 \%$, c) $5 \%$ and d) $10 \%$ PCBM doped $\mathrm{ZnO}$ interlayer

\section{Conclusion}


Undoped and various PCBM doped Al/PCBM:ZnO/p-Si devices were produced by spin coating method as well as thermal evaporation method. The electrical characteristics of the obtained devices were performed by $I$ $V$ measurements in the dark and under varying illumination conditions according to having various PCBM doped $\mathrm{ZnO}$ interfacial layers. The PCBM doping changed the morphology of the $\mathrm{ZnO}$ interfacial layer according to AFM images. The obtained devices showed good photodiode properties and rectifying ratios in the vicinity of $10^{3}$ rates in the dark and under varying illumination conditions. The junction parameters of the produced devices were calculated by using TE, Norde, and Cheung models. The ideality factor values determined from Cheung model are 4.74, 5.47, 3.60 and 7.72 for undoped, 3\%, 5\% and 10\% PCBM doped devices, respectively. These results are compatible with the values found by TE method. The barrier height values calculated from Norde model are $0.82,0.72,0.93$ and 0.67 for undoped, 3\%, 5\% and 10\% PCBM doped devices, respectively and these results are slightly bigger than the values found other methods. The series resistance values calculated from Norde model are higher than other values that obtained from the TE and Chung method. The current transient results reveal that the PCBM doping can be used to increase the photoresponse capacity of the MS devices.

\section{Acknowledgments}

The author would like to thank Dr. Murat Yildırım and Dr. Adem Kocyigit for fruitful collaborations, invigorating discussions and comments.

\section{References}

[1] I. Orak, A. Kocyigit, A. Turut, The surface morphology properties and respond illumination impact of $\mathrm{ZnO} / \mathrm{n}-\mathrm{Si}$ photodiode by prepared atomic layer deposition technique, J. Alloys Compd. 691 (2017) 873879. doi:10.1016/j.jallcom.2016.08.295.

[2] M. Jang, Scalability of Schottky barrier metal-oxide-semiconductor transistors, Nano Converg. 3 (2016) 11. doi:10.1186/s40580-016-0071-0.

[3] P. Kumar, B. Bhowmick, Source-Drain Junction Engineering Schottky Barrier MOSFETs and their Mixed Mode Application, Silicon. 12 (2019) 821-830. doi:10.1007/s12633-019-00170-0.

[4] K. Xu, Silicon MOS Optoelectronic Micro-Nano Structure Based on Reverse-Biased PN Junction, Phys. Status Solidi Appl. Mater. Sci. 216 (2019) 1800868. doi:10.1002/pssa.201800868.

[5] M. Farhat, S. Kais, F.H. Alharbi, Plasmonically Enhanced Schottky Photovoltaic Devices, Sci. Rep. 7 (2017) 1-9. doi:10.1038/s41598-017-14528-0.

[6] B.A. Gozeh, A. Karabulut, A. Yildiz, F. Yakuphanoglu, Solar light responsive ZnO nanoparticles adjusted using Cd and La Co-dopant photodetector, J. Alloys Compd. 732 (2018) 16-24. doi:10.1016/J.JALLCOM.2017.10.167.

[7] A. Kocyigit, M. Yılmaz, Ş. Aydoğan, Ü. İncekara, The effect of measurements and layer coating homogeneity of AB on the Al/AB/p-Si devices, J. Alloys Compd. 790 (2019) 388-396. doi:10.1016/j.jallcom.2019.03.179.

[8] B. Shan, A. Nayak, O.F. Williams, D.C. Yost, N.F. Polizzi, Y. Liu, N. Zhou, Y. Kanai, A.M. Moran, 
M.J. Therien, T.J. Meyer, Excitation energy-dependent photocurrent switching in a single-molecule photodiode, Proc. Natl. Acad. Sci. U. S. A. 116 (2019) 16198-16203. doi:10.1073/pnas.1907118116.

[9] A. Mekki, R.O. Ocaya, A. Dere, A.A. Al-Ghamdi, K. Harrabi, F. Yakuphanoglu, New photodiodes based graphene-organic semiconductor hybrid materials, Synth. Met. 213 (2016) 47-56.

doi:10.1016/j.synthmet.2015.12.026.

[10] O.S. Cifci, M. Bakir, J.L. Meyer, A. Kocyigit, Morphological and electrical properties of ATSP/p-Si photodiode, Mater. Sci. Semicond. Process. 74 (2018) 175-182. doi:10.1016/J.MSSP.2017.10.039.

[11] S.J. Chen, D.C. Hovde, K.A. Peterson, A.W. Marshall, Fire detection using smoke and gas sensors, Fire Saf. J. 42 (2007) 507-515. doi:10.1016/j.firesaf.2007.01.006.

[12] E. Vidal, P. Andersen, J. Stoustrup, T.S. Pedersen, A study on the surface defects of a compact disk, in: IEEE Conf. Control Appl. - Proc., 2001: pp. 101-104. doi:10.1109/cca.2001.973845.

[13] S. Wageh, W.A. Farooq, A. Tataroğlu, A. Dere, A.G. Al-Sehemi, A.A. Al-Ghamdi, F. Yakuphanoglu, A photodiode based on PbS nanocrystallites for FYTRONIX solar panel automatic tracking controller, Phys. B Condens. Matter. 527 (2017) 44-51. doi:10.1016/J.PHYSB.2017.09.114.

[14] H. Kacus, Y. Sahin, S. Aydogan, U. Incekara, M. Yilmaz, Co/aniline blue/silicon sandwich hybrid heterojunction for photodiode and low-temperature applications, J. Sandw. Struct. Mater. (2020) 109963622090994. doi:10.1177/1099636220909946.

[15] M.O. Erdal, A. Kocyigit, M. Y1ldırım, Temperature dependent current-voltage characteristics of $\mathrm{Al} / \mathrm{TiO} 2 / \mathrm{n}-\mathrm{Si}$ and Al/Cu:TiO2/n-Si devices, Mater. Sci. Semicond. Process. 103 (2019) 104620. doi:10.1016/j.mssp.2019.104620.

[16] İ. Orak, The performances photodiode and diode of $\mathrm{ZnO}$ thin film by atomic layer deposition technique, Solid State Commun. 247 (2016) 17-22. doi:10.1016/j.ssc.2016.08.004.

[17] M.O. Erdal, A. Kocyigit, M. Y1ldırım, The C-V characteristics of TiO2/p-Si/Ag, GNR doped TiO2/p$\mathrm{Si} / \mathrm{Ag}$ and MWCNT doped TiO2/p-Si/Ag heterojunction devices, Chinese J. Phys. 64 (2020) 163-173. doi:10.1016/j.cjph.2019.12.021.

[18] Z.L. Wang, Nanostructures of zinc oxide, Mater. Today. 7 (2004) 26-33. doi:10.1016/S13697021(04)00286-X.

[19] Ü. Özgür, Y.I. Alivov, C. Liu, A. Teke, M.A. Reshchikov, S. Doğan, V. Avrutin, S.-J. Cho, H. Morkoç, A comprehensive review of $\mathrm{ZnO}$ materials and devices, J. Appl. Phys. 98 (2005) 041301. doi:10.1063/1.1992666.

[20] Ü. Ozgur, D. Hofstetter, H. Morkoç, $\mathrm{ZnO}$ devices and applications: A review of current status and future prospects, Proc. IEEE. 98 (2010) 1255-1268. doi:10.1109/JPROC.2010.2044550.

[21] A. Kocyigit, M.O. Erdal, M. Y1ldırım, Effect of Indium Doping on Optical Parameter Properties of SolGel-Derived ZnO Thin Films, Zeitschrift Für Naturforsch. A. 74 (2019) 915-923. doi:10.1515/zna-20190070 . 
[22] F. Yakuphanoglu, S. Mansouri, Photosensitivity n-channel $\mathrm{ZnO}$ phototransistor for optoelectronic applications: Modeling of ZnO TFT, Microelectron. Reliab. 51 (2011) 2200-2204. doi:10.1016/j.microrel.2011.06.007.

[23] J. Xu, Q. Pan, Y. Shun, Z. Tian, Grain size control and gas sensing properties of $\mathrm{ZnO}$ gas sensor, Sensors Actuators, B Chem. 66 (2000) 277-279. doi:10.1016/S0925-4005(00)00381-6.

[24] S.H. Ko, D. Lee, H.W. Kang, K.H. Nam, J.Y. Yeo, S.J. Hong, C.P. Grigoropoulos, H.J. Sung, Nanoforest of hydrothermally grown hierarchical $\mathrm{ZnO}$ nanowires for a high efficiency dye-sensitized solar cell, Nano Lett. 11 (2011) 666-671. doi:10.1021/n11037962.

[25] S. Liang, H. Sheng, Y. Liu, Z. Huo, Y. Lu, H. Shen, ZnO Schottky ultraviolet photodetectors, J. Cryst. Growth. 225 (2001) 110-113. doi:10.1016/S0022-0248(01)00830-2.

[26] I.-S. Jeong, J.H. Kim, S. Im, Ultraviolet-enhanced photodiode employing n-ZnO/p-Si structure, Appl. Phys. Lett. 83 (2003) 2946-2948. doi:10.1063/1.1616663.

[27] Ş. Aydoğan, M.L. Grilli, M. Yilmaz, Z. Çaldiran, H. Kaçuş, A facile growth of spray based ZnO films and device performance investigation for Schottky diodes: Determination of interface state density distribution, J. Alloys Compd. 708 (2017) 55-66. doi:10.1016/j.jallcom.2017.02.198.

[28] A. Raidou, M. Lharch, K. Nouneh, M. Aggour, A. Qachaou, L. Laanab, M. Fahoume, Effect of substrate on $\mathrm{ZnO}$ thin films grown by SILAR method, in: 2014 Int. Renew. Sustain. Energy Conf., IEEE, 2014: pp. 695-700. doi:10.1109/IRSEC.2014.7059829.

[29] D.G. Baik, S.M. Cho, Application of sol-gel derived films for $\mathrm{ZnO} / \mathrm{n}-\mathrm{Si}$ junction solar cells, Thin Solid Films. 354 (1999) 227-231. doi:10.1016/S0040-6090(99)00559-3.

[30] H. Endo, M. Sugibuchi, K. Takahashi, S. Goto, S. Sugimura, K. Hane, Y. Kashiwaba, Schottky ultraviolet photodiode using a $\mathrm{ZnO}$ hydrothermally grown single crystal substrate, Appl. Phys. Lett. 90 (2007) 121906. doi:10.1063/1.2715100.

[31] I. Orak, A. Kocyigit, S. Alindal, Electrical and dielectric characterization of Au/ZnO/n-Si device depending frequency and voltage, Chinese Phys. B. 26 (2017) 028102-028102-7. doi:10.1088/16741056/26/2/028102.

[32] N. Bouhssira, S. Abed, E. Tomasella, J. Cellier, A. Mosbah, M.S. Aida, M. Jacquet, Influence of annealing temperature on the properties of $\mathrm{ZnO}$ thin films deposited by thermal evaporation, Appl. Surf. Sci. 252 (2006) 5594-5597. doi:10.1016/j.apsusc.2005.12.134.

[33] H. Ferhati, F. Djeffal, A. Benhaya, N. Martin, Highly sensitive, ultra-low dark current, self-powered solar-blind ultraviolet photodetector based on $\mathrm{ZnO}$ thin-film with an engineered rear metallic layer, Mater. Sci. Semicond. Process. 110 (2020) 104957. doi:10.1016/j.mssp.2020.104957.

[34] M. Yilmaz, Z. Caldiran, A.R. Deniz, S. Aydogan, R. Gunturkun, A. Turut, Preparation and characterization of sol-gel-derived $\mathrm{n}-\mathrm{ZnO}$ thin film for Schottky diode application, Appl. Phys. A Mater. Sci. Process. 119 (2015) 547-552. doi:10.1007/s00339-015-8987-5. 
[35] Ö.F. Yüksel, M. Kuş, M. Yıldırım, Capacitance and Conductance-Frequency Characteristics of Au/n-Si Schottky Structure with Perylene-Diimide (PDI) Organic Interlayer, J. Electron. Mater. 46 (2017) 882887. doi:10.1007/s11664-016-4999-y.

[36] Y. Nam, I. Hwang, S. Oh, S. Lee, K. Lee, S. Hong, J. Kim, T. Choi, B. Ho Park, Switchable Schottky diode characteristics induced by electroforming process in Mn-doped $\mathrm{ZnO}$ thin films, Appl. Phys. Lett. 102 (2013) 162105. doi:10.1063/1.4803088.

[37] A. Kocyigit, İ. Orak, A. Turut, Temperature dependent dielectric properties of $\mathrm{Au} / \mathrm{ZnO} / n-\mathrm{Si}$ heterojuntion, Mater. Res. Express. (2018). doi:10.1088/2053-1591/aab2e3.

[38] M. Sahal, B. Hartiti, A. Ridah, M. Mollar, B. Marí, Structural, electrical and optical properties of ZnO thin films deposited by sol-gel method, Microelectronics J. 39 (2008) 1425-1428. doi:10.1016/j.mejo.2008.06.085.

[39] M.Z. Hasan, C.L. Kane, Colloquium: Topological insulators, Rev. Mod. Phys. 82 (2010) 3045-3067. doi:10.1103/RevModPhys.82.3045.

[40] F. Aslan, H. Esen, F. Yakuphanoglu, Electrical and fotoconducting characterization of $\mathrm{Al} /$ coumarin:ZnO/Al novel organic-inorganic hybrid photodiodes, J. Alloys Compd. 789 (2019) 595606. doi:10.1016/j.jallcom.2019.03.090.

[41] M. Y1ldirım, M.O. Erdal, A. Kocyigit, The effect of indium doping concentration on the electrical and dielectric properties of Al/In:ZnO/p-Si heterojunctions, Phys. B Condens. Matter. 572 (2019) 153-160. doi:10.1016/j.physb.2019.07.055.

[42] J.H. Koo, S. Jeong, H.J. Shim, D. Son, J. Kim, D.C. Kim, S. Choi, J.-I. Hong, D.-H. Kim, Wearable Electrocardiogram Monitor Using Carbon Nanotube Electronics and Color-Tunable Organic LightEmitting Diodes, ACS Nano. 11 (2017) 10032-10041. doi:10.1021/acsnano.7b04292.

[43] C. Wang, X. Chen, F. Chen, J. Shao, Organic photodetectors based on copper phthalocyanine films prepared by a multiple drop casting method, Org. Electron. 66 (2019) 183-187. doi:10.1016/j.orgel.2018.12.035.

[44] V. Sharma, H. Sharma, R. Vyas, K. Sachdev, Polymer-metal-polymer (PMP) multilayer transparent electrode for organic optoelectronics, Mater. Des. 156 (2018) 135-142. doi:10.1016/j.matdes.2018.06.026.

[45] J.-H. Huang, J.-H. Fang, C.-C. Liu, C.-W. Chu, Effective Work Function Modulation of Graphene/Carbon Nanotube Composite Films As Transparent Cathodes for Organic Optoelectronics, ACS Nano. 5 (2011) 6262-6271. doi:10.1021/nn201253w.

[46] B. Nie, J.G. Hu, L.B. Luo, C. Xie, L.H. Zeng, P. Lv, F.Z. Li, J.S. Jie, M. Feng, C.Y. Wu, Y.Q. Yu, S.H. $\mathrm{Yu}$, Monolayer graphene film on zno nanorod array for high-performance schottky junction ultraviolet photodetectors, Small. 9 (2013) 2872-2879. doi:10.1002/smll.201203188.

[47] C.-C. Cheng, J.-Y. Zhan, Y.-M. Liao, T.-Y. Lin, Y.-P. Hsieh, Y.-F. Chen, Self-powered and broadband photodetectors based on graphene/ZnO/silicon triple junctions, Appl. Phys. Lett. 109 (2016) 053501. 
doi:10.1063/1.4960357.

[48] D. Shao, M. Yu, J. Lian, S. Sawyer, Heterojunction photodiode fabricated from multiwalled carbon nanotube/ZnO nanowire/p-silicon composite structure, Appl. Phys. Lett. 102 (2013) 021107. doi:10.1063/1.4776691.

[49] A.M. Bazargan, F. Sharif, S. Mazinani, N. Naderi, High-performance transparent ultraviolet photodetector based on thermally reduced graphene oxide and $\mathrm{ZnO}$ thin films, J. Mater. Sci. Mater. Electron. 28 (2017) 11108-11113. doi:10.1007/s10854-017-6896-4.

[50] M.M. Koç, N. Aslan, M. Erkovan, B. Aksakal, O. Uzun, W.A. Farooq, F. Yakuphanoğlu, Electrical characterization of solar sensitive zinc oxide doped-amorphous carbon photodiode, Optik (Stuttg). 178 (2019) 316-326. doi:10.1016/j.ijleo.2018.10.008.

[51] M.T. Dang, L. Hirsch, G. Wantz, P3HT:PCBM, best seller in polymer photovoltaic research, Adv. Mater. 23 (2011) 3597-3602. doi:10.1002/adma.201100792.

[52] S. Antohe, S. Iftimie, L. Hrostea, V.A. Antohe, M. Girtan, A critical review of photovoltaic cells based on organic monomeric and polymeric thin film heterojunctions, Thin Solid Films. 642 (2017) 219-231. doi:10.1016/J.TSF.2017.09.041.

[53] F. Piersimoni, S. Chambon, K. Vandewal, R. Mens, T. Boonen, A. Gadisa, M. Izquierdo, S. Filippone, B. Ruttens, J. D’Haen, N. Martin, L. Lutsen, D. Vanderzande, P. Adriaensens, J. V. Manca, Influence of Fullerene Ordering on the Energy of the Charge-Transfer State and Open-Circuit Voltage in Polymer:Fullerene Solar Cells, J. Phys. Chem. C. 115 (2011) 10873-10880. doi:10.1021/jp110982m.

[54] L. Li, G. Lu, S. Li, H. Tang, X. Yang, Epitaxy-Assisted Creation of PCBM Nanocrystals and Its Application in Constructing Optimized Morphology for Bulk-Heterojunction Polymer Solar Cells, J. Phys. Chem. B. 112 (2008) 15651-15658. doi:10.1021/jp8081529.

[55] E.L. Lim, C.C. Yap, M.A. Mat Teridi, C.H. Teh, A.R. Bin Mohd Yusoff, M.H. Hj Jumali, A review of recent plasmonic nanoparticles incorporated P3HT: PCBM organic thin film solar cells, Org. Electron. 36 (2016) 12-28. doi:10.1016/j.orgel.2016.05.029.

[56] A. Swinnen, I. Haeldermans, M. vande Ven, J. D’Haen, G. Vanhoyland, S. Aresu, M. D’Olieslaeger, J. Manca, Tuning the Dimensions of C60-Based Needlelike Crystals in Blended Thin Films, Adv. Funct. Mater. 16 (2006) 760-765. doi:10.1002/adfm.200500812.

[57] Y. Bai, H. Yu, Z. Zhu, K. Jiang, T. Zhang, N. Zhao, S. Yang, H. Yan, High performance inverted structure perovskite solar cells based on a PCBM:polystyrene blend electron transport layer, J. Mater. Chem. A. 3 (2015) 9098-9102. doi:10.1039/C4TA05309E.

[58] S. Park, W. Jang, D.H. Wang, Alignment of Cascaded Band-Gap via PCBM/ZnO Hybrid Interlayers for Efficient Perovskite Photovoltaic Cells, Macromol. Res. 26 (2018) 472-476. doi:10.1007/s13233-0186086-0.

[59] F. Yakuphanoglu, Photovoltaic properties of hybrid organic/inorganic semiconductor photodiode, Synth. Met. 157 (2007) 859-862. doi:10.1016/j.synthmet.2007.08.012. 
[60] H.H. Gullu, D.E. Yildiz, A. Kocyigit, M. Yıldırım, Electrical properties of A1/PCBM:ZnO/p-Si heterojunction for photodiode application, J. Alloys Compd. 827 (2020) 154279. doi:10.1016/j.jallcom.2020.154279.

[61] Y. Badali, Ş. Altındal, İ. Uslu, Dielectric properties, electrical modulus and current transport mechanisms of $\mathrm{Au} / \mathrm{ZnO} / \mathrm{n}-\mathrm{Si}$ structures, Prog. Nat. Sci. Mater. Int. 28 (2018) 325-331. doi:10.1016/J.PNSC.2018.05.003.

[62] A. Kathalingam, H.-S. Kim, H.-M. Park, S. Valanarasu, T. Mahalingam, Effect of indium on photovoltaic property of $\mathrm{n}-\mathrm{ZnO} / \mathrm{p}$-Si heterojunction device prepared using solution-synthesized $\mathrm{ZnO}$ nanowire film, J. Photonics Energy. 5 (2015) 053085. doi:10.1117/1.jpe.5.053085.

[63] M. Y1ldırım, A. Kocyigit, Characterization of Al/In:ZnO/p-Si photodiodes for various In doped level to ZnO interfacial layers, J. Alloys Compd. 768 (2018) 1064-1075. doi:10.1016/j.jallcom.2018.07.295.

[64] S.M. Mortuza, S. Banerjee, Molecular modeling study of agglomeration of 6,6-phenyl-C61-butyric acid methyl ester in solvents, J. Chem. Phys. 137 (2012) 244308. doi:10.1063/1.4772759.

[65] R.H. Al Orainy, A.A. Hendi, Fabrication and electrical characterization of CdO/p-Si photosensors, Microelectron. Eng. 127 (2014) 14-20. doi:10.1016/j.mee.2014.02.014.

[66] E.H. Rhoderick, R.H. Williams, Metal-semiconductor contacts, 2nd ed., Clarendon Press ;;Oxford University Press, Oxford [England] ;New York, 1988.

[67] Ş. Karataş, Ş. Altindal, A. Türüt, A. Özmen, Temperature dependence of characteristic parameters of the H-terminated Sn/p-Si(1 0 0) Schottky contacts, Appl. Surf. Sci. 217 (2003) 250-260. doi:10.1016/S01694332(03)00564-6.

[68] O.S. Cifci, A. Kocyigit, P. Sun, Perovskite/p-Si photodiode with ultra-thin metal cathode, Superlattices Microstruct. 120 (2018) 492-500. doi:10.1016/J.SPMI.2018.06.009.

[69] M. Yildirım, Characterization of the framework of $\mathrm{Cu}$ doped TiO2 layers: An insight into optical, electrical and photodiode parameters, J. Alloys Compd. 773 (2019) 890-904. doi:10.1016/j.jallcom.2018.09.276.

[70] S. Kyoung, E.-S. Jung, M.Y. Sung, Post-annealing processes to improve inhomogeneity of Schottky barrier height in Ti/Al 4H-SiC Schottky barrier diode, Microelectron. Eng. 154 (2016) 69-73. doi:10.1016/j.mee.2016.01.013.

[71] Altindal, T. Tunç, H. Tecimer, I. Yücedag, Electrical and photovoltaic pro[1] Altindal, T. Tunç, H. Tecimer, I. Yücedag, Electrical and photovoltaic properties of $\mathrm{Au} /(\mathrm{Ni}, \mathrm{Zn})$-doped PVA/n-Si structures in dark and under $250 \mathrm{~W}$ illumination level, Mater. Sci. Semicond. Process. 28 (2014) 48-53. doi:1, Mater. Sci. Semicond. Process. 28 (2014) 48-53. doi:10.1016/j.mssp.2014.05.007.

[72] B. Tatar, A.E. Bulgurcuoglu, P. Gokdemir, P. Aydogan, D. Yilmazer, O. ozdemir, K. Kutlu, Electrical and photovoltaic properties of Cr/Si Schottky diodes, Int. J. Hydrogen Energy. 34 (2009) 5208-5212. doi:10.1016/j.ijhydene.2008.10.040. 
[73] M. Yıldırım, A. Kocyigit, A. Sarılmaz, F. Ozel, The effect of the triangular and spherical shaped CuSbS2 structure on the electrical properties of Au/CuSbS2/p-Si photodiode, J. Mater. Sci. Mater. Electron. 30 (2019) 332-339. doi:10.1007/s10854-018-0297-1.

[74] S.K. Singh, P. Hazra, S. Tripathi, P. Chakrabarti, Performance analysis of RF-sputtered ZnO/Si heterojunction UV photodetectors with high photo-responsivity, Superlattices Microstruct. 91 (2016) 6269. doi:10.1016/j.spmi.2015.12.036.

[75] M. Ikram, R. Murray, A. Hussain, S. Ali, S. Ismat Shah, Hybrid organic solar cells using both $\mathrm{ZnO}$ and PCBM as electron acceptor materials, Mater. Sci. Eng. B. 189 (2014) 64-69. doi:10.1016/j.mseb.2014.08.005.

[76] S.K. Cheung, N.W. Cheung, Extraction of Schottky diode parameters from forward current-voltage characteristics, Appl. Phys. Lett. 49 (1986) 85. doi:10.1063/1.97359.

[77] H. Norde, A modified forward I-V plot for Schottky diodes with high series resistance, J. Appl. Phys. 50 (1979) 5052-5053. doi:10.1063/1.325607.

[78] Ş. Karataş, Effect of series resistance on the electrical characteristics and interface state energy distributions of Sn/p-Si (MS) Schottky diodes, Microelectron. Eng. 87 (2010) 1935-1940. doi:10.1016/j.mee.2009.11.168.

[79] M. Yıldırım, A. Kocyigit, A. Sarilmaz, S.S. Ozel, M. Kus, F. Ozel, Ternary CuCo2S4 Thiospinel Nanocrystal-Coated Photodiode with Improved Photoresponsivity and Acceptance Angles for Optoelectronic Applications, J. Electron. Mater. 49 (2020) 949-958. doi:10.1007/s11664-019-07841-z.

[80] A. Tataroğlu, Ş. Altındal, Y. Azizian-Kalandaragh, Comparison of electrical properties of MS and MPS type diode in respect of (In2O3-PVP) interlayer, Phys. B Condens. Matter. 576 (2020) 411733. doi:10.1016/j.physb.2019.411733.

[81] N. Cho, H.L. Yip, S.K. Hau, K.S. Chen, T.W. Kim, J.A. Davies, D.F. Zeigler, A.K.Y. Jen, N-Doping of thermally polymerizable fullerenes as an electron transporting layer for inverted polymer solar cells, J. Mater. Chem. 21 (2011) 6956-6961. doi:10.1039/c1jm10214a.

[82] İ. Orak, K. Ejderha, A. Turut, The electrical characterizations and illumination response of Co/N-type GaP junction device, Curr. Appl. Phys. 15 (2015) 1054-1061. doi:10.1016/j.cap.2015.05.014.

[83] Ş. Karataş, N. Yildirim, A. Türüt, Electrical properties and interface state energy distributions of $\mathrm{Cr} / \mathrm{n}-\mathrm{Si}$ Schottky barrier diode, Superlattices Microstruct. 64 (2013) 483-494. doi:10.1016/j.spmi.2013.10.015.

[84] D. Chi, S. Qu, Z. Wang, J. Wang, High efficiency P3HT:PCBM solar cells with an inserted PCBM layer, J. Mater. Chem. C. 2 (2014) 4383. doi:10.1039/c4tc00003j. 


\section{Figures}
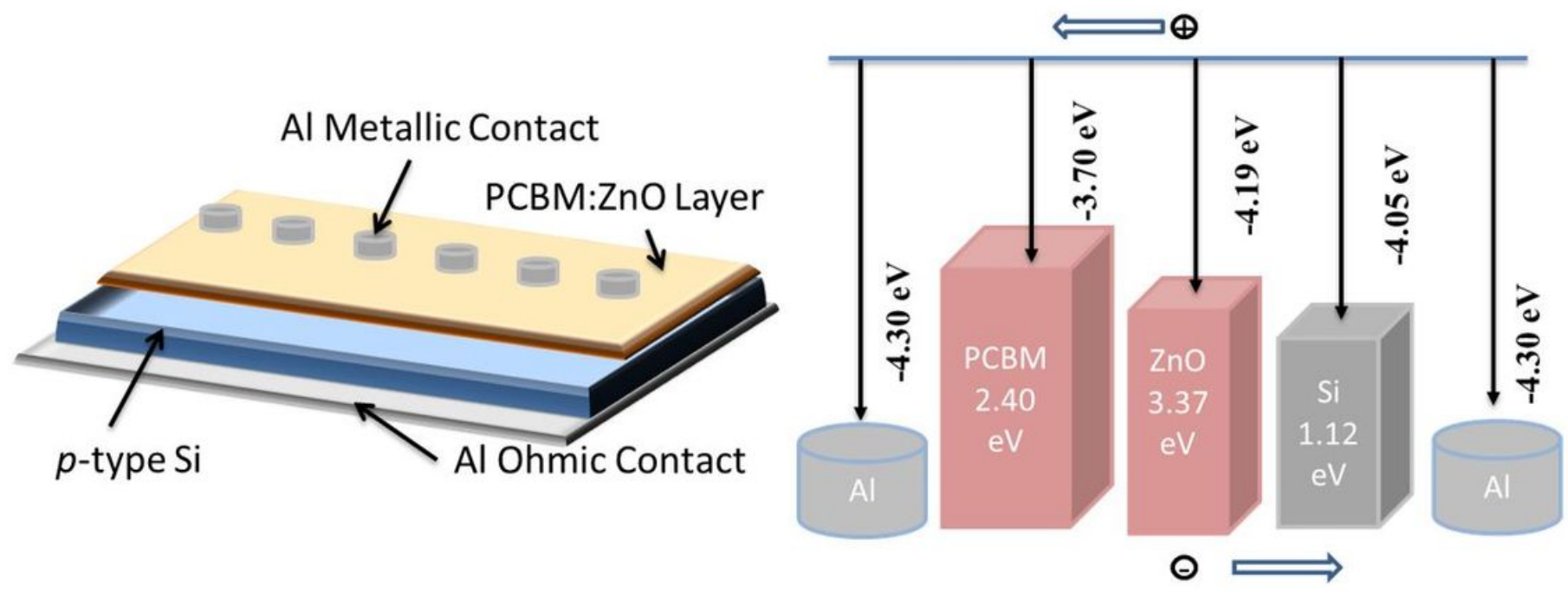

Figure 1

The schematic drawing and band diagrams of the fabricated Al/PCBM:ZnO/p-Si devices
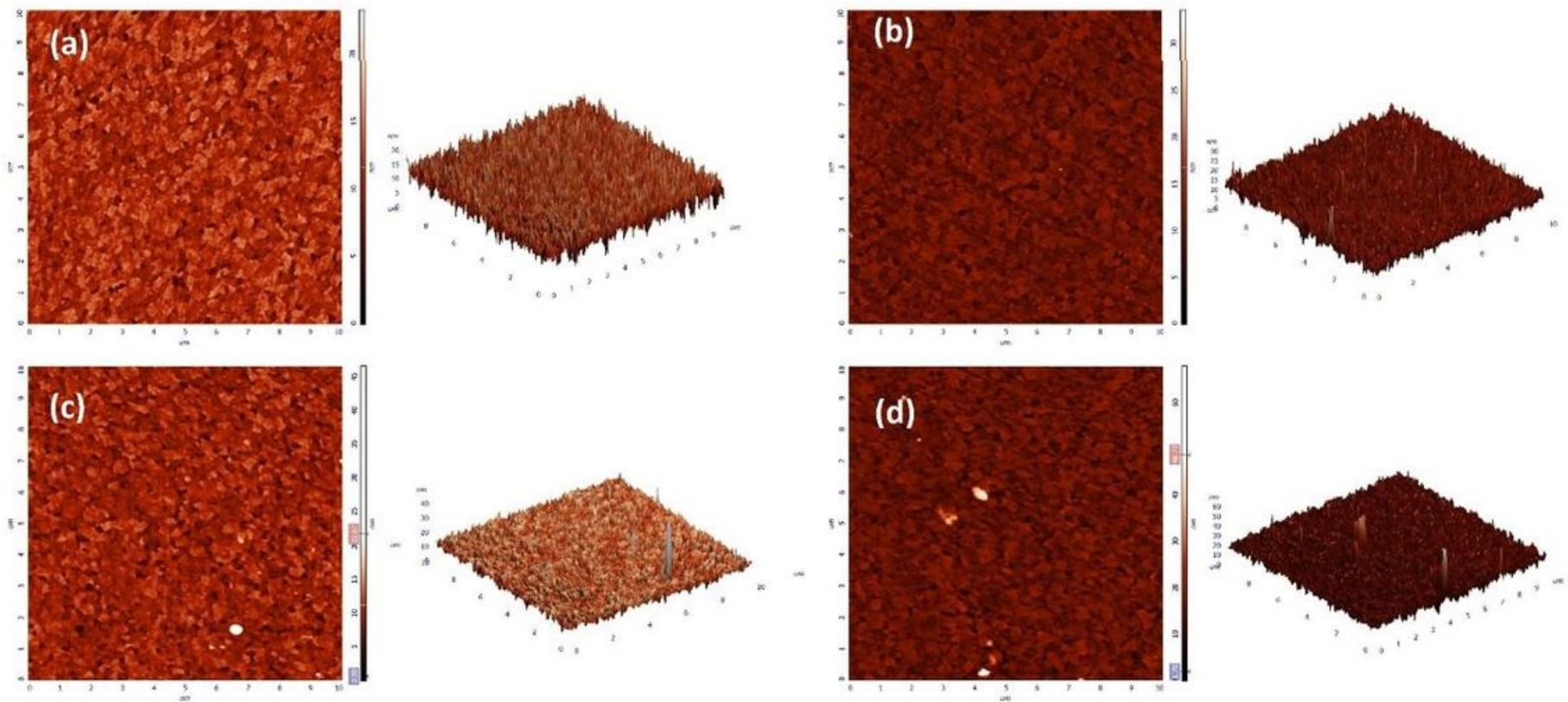

Figure 2

The AFM morphology pictures of a) undoped b) 3\%, c) 5\% and d) 10\% PCBM doped Al/PCBM:ZnO/p-Si devices 

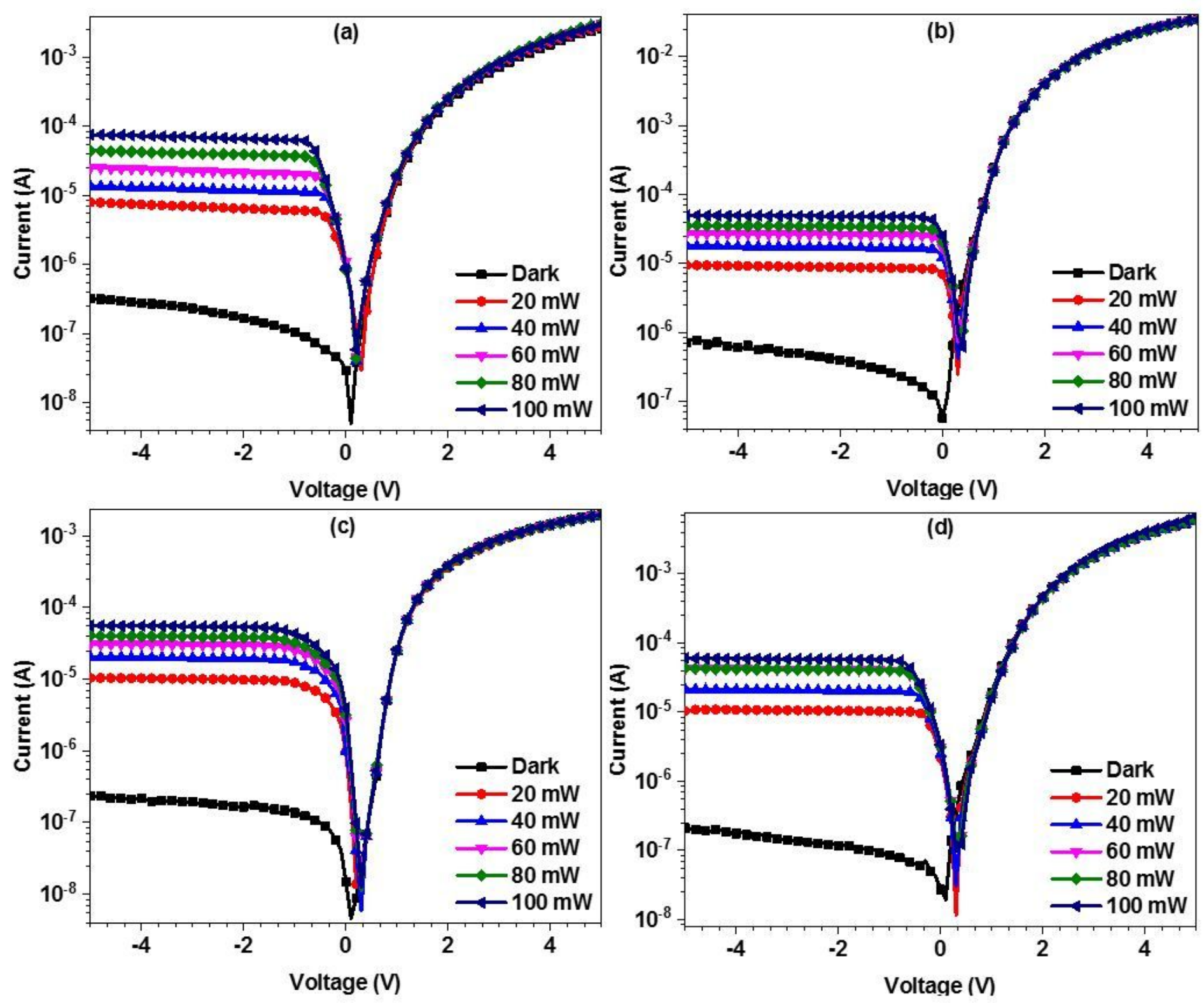

Figure 3

I-V plots of a) undoped b) $3 \%$, c) $5 \%$ and d) $10 \%$ PCBM doped Al/PCBM:ZnO/p-Si devices 

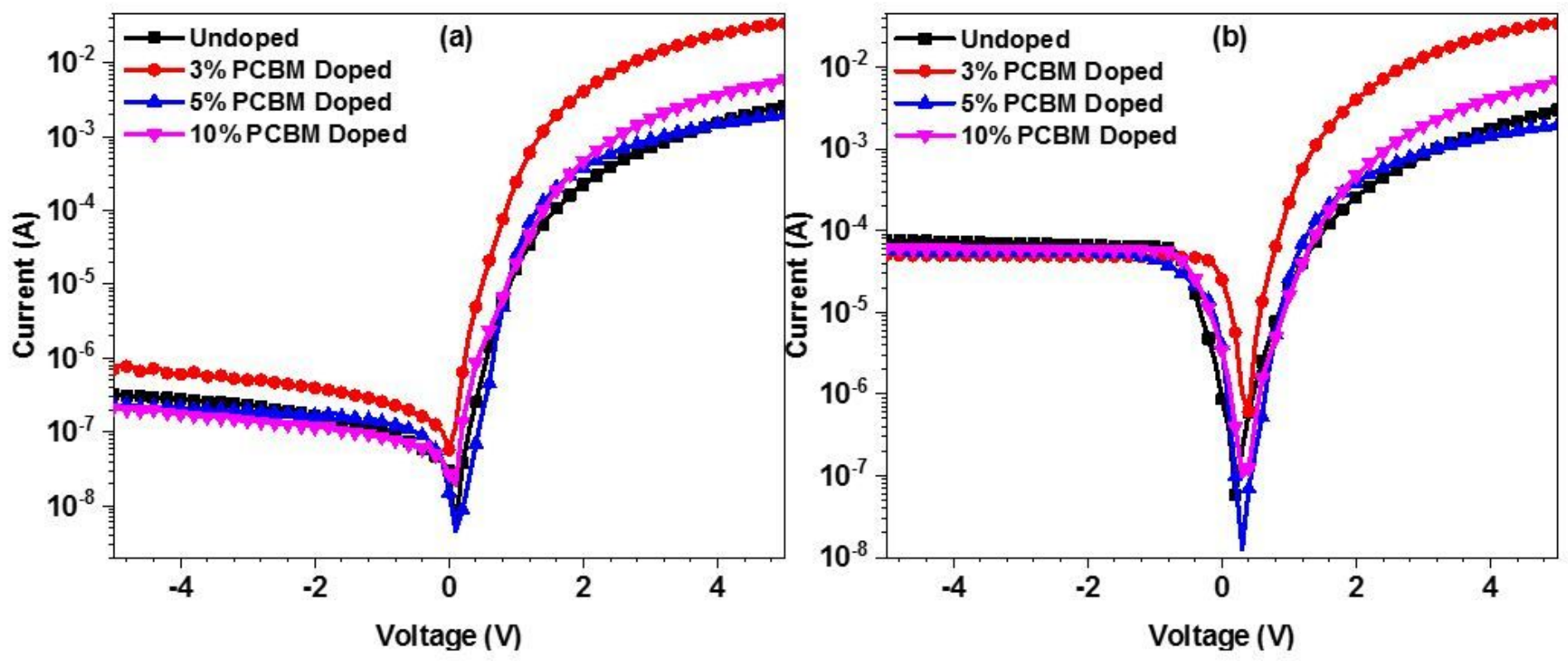

Figure 4

I-V plots of the undoped and various PCBM amounts doped Al/PCBM:ZnO/p-Si devices a) in the dark and b) under $100 \mathrm{~mW}$ light intensity for comparison 

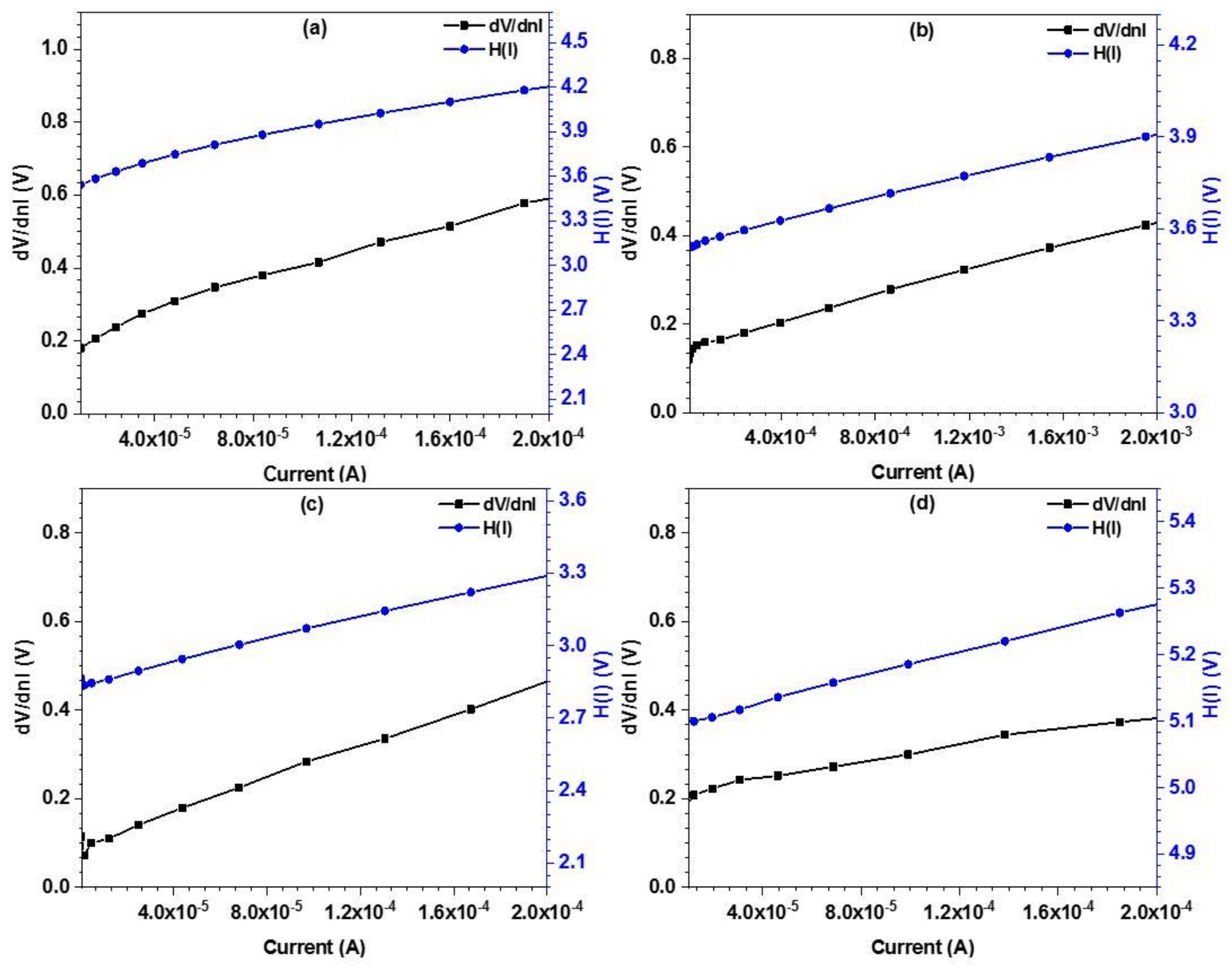

Figure 5

$\mathrm{dV} / \mathrm{d}(\mathrm{InI} \mathrm{I})-\mathrm{I}$ and $\mathrm{H}(\mathrm{I})-\mathrm{I}$ plots of the Al/PCBM:ZnO/p-Si devices a) for undoped b) $3 \%$, c) $5 \%$ and d) $10 \%$ PCBM doped ZnO interlayer 

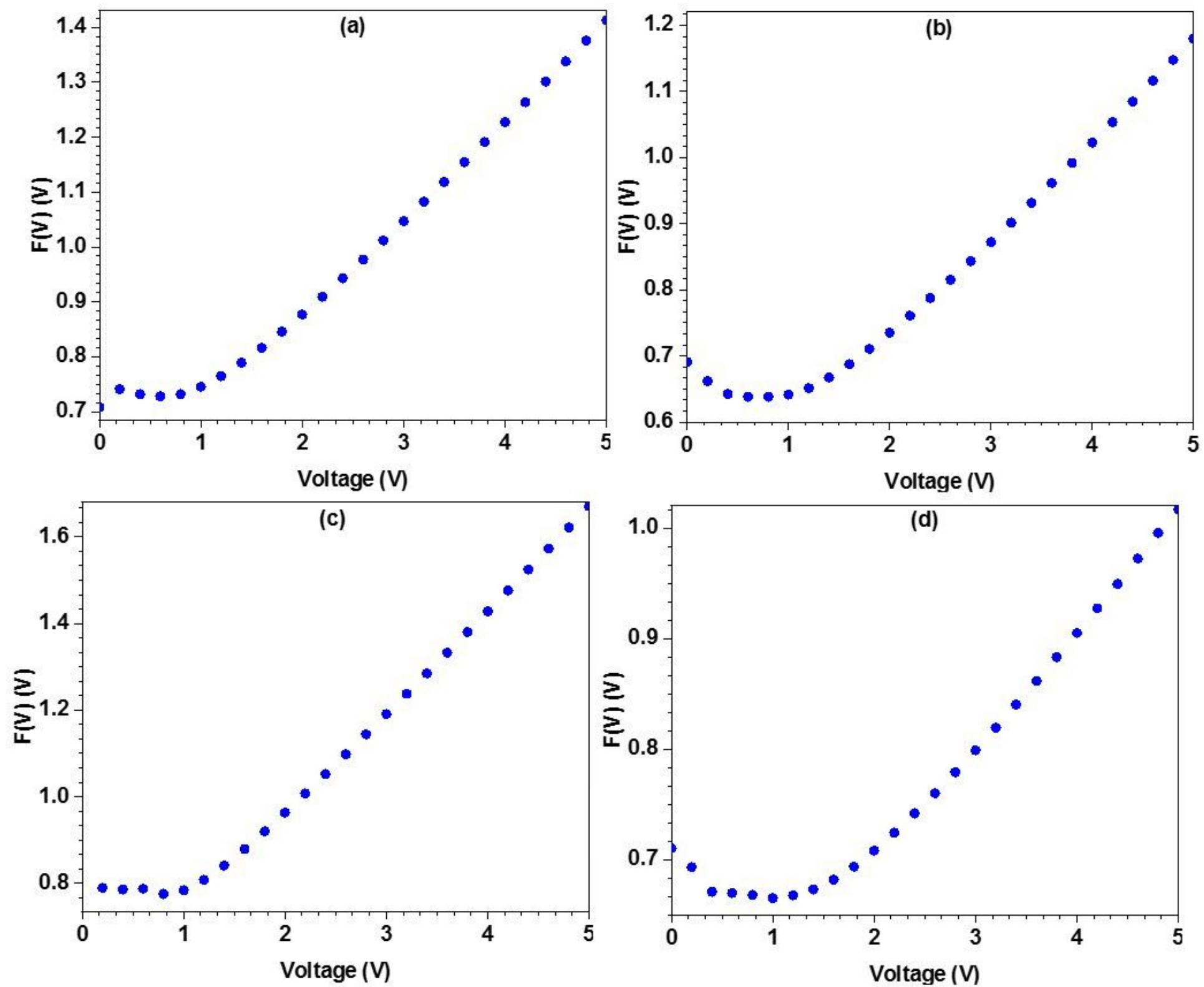

Figure 6

F(V)-V graphs of the Al/PCBM:ZnO/p-Si devices a) for undoped b) $3 \%, c) 5 \%$ and d) $10 \%$ PCBM doped ZnO interlayer 

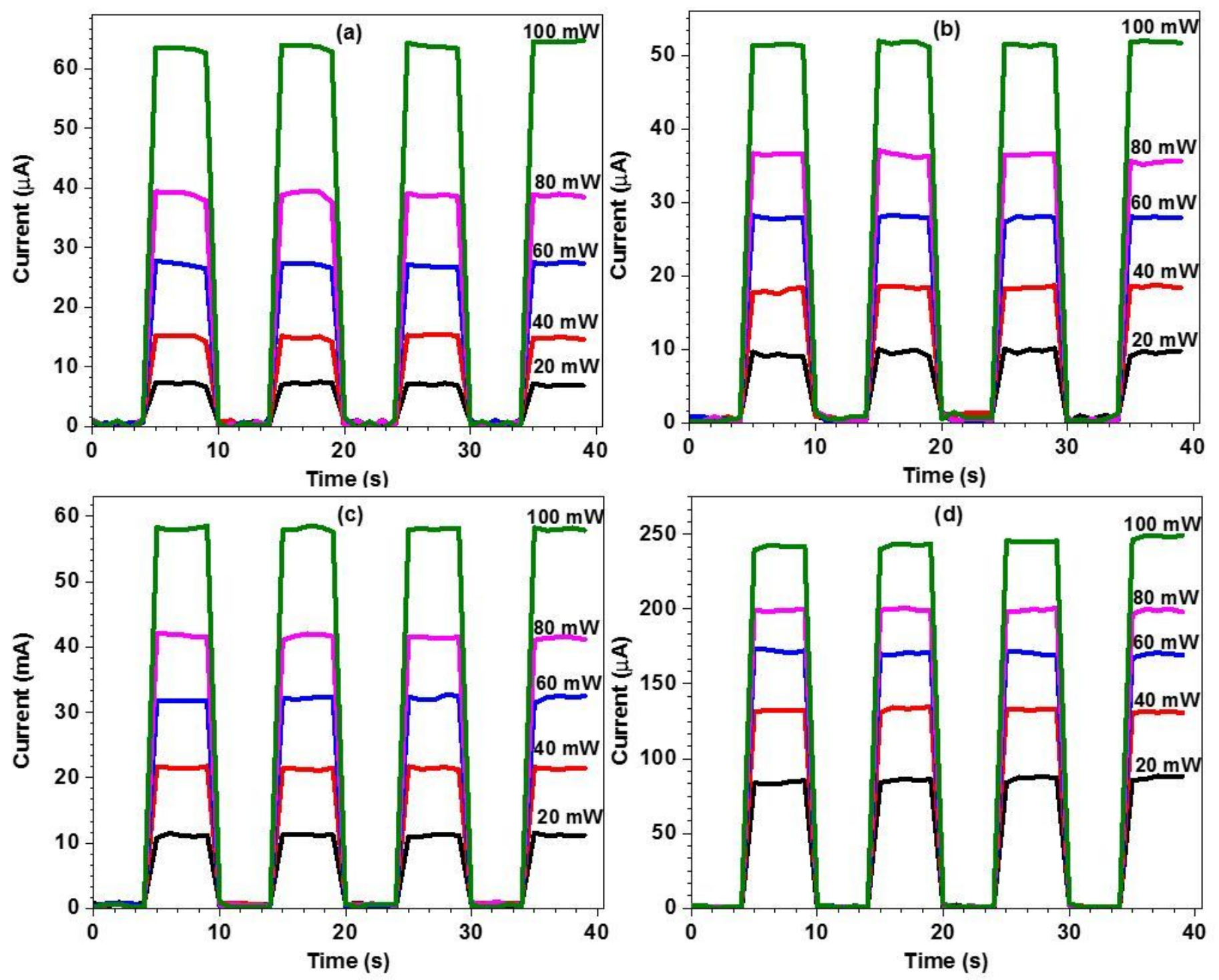

Figure 7

The current transient measurements of the various PCBM doped Al/PCBM:ZnO/p-Si devices a) for undoped b) $3 \%$, c) $5 \%$ and d) $10 \%$ PCBM doped ZnO interlayer 